JIPS, Vol. 2 No. 1

Halaman: 105 - 116

Mei 2021
Jurnal Inovasi Pembelajaran di Sekolah

DOI: https://doi.org/10.51874/jips.v1i01.8

ISSN 2774-9363 (Cetak)

ISSN 2774-9746 (Online)
IIPS

Jurnal Inovasi Pembelajaran di Sekolah

\title{
Pengaruh Model Pembelajaran Teams Games Tournament Terhadap Hasil Belajar Pembelajaran Tematik Integratif Siswa Kelas IV SDN Lamper Kidul 02 Semarang
}

\author{
Maria Astuti \\ SDN Lamper Kidul 02 Semarang Jl. Sompok Baru No.87 Semarang \\ e-mail: mariaastuti70@gmail.com
}

\begin{abstract}
Abstrak
Penelitian ini bertujuan untuk mengetahui perbedaan hasil belajar pembelajaran tematik antara siswa yang mengikuti model pembelajaran TGT dengan siswa yang mengikuti model pembelajaran langsung siswa kelas IV SDN Lamper Kidul 02 Semarang. Penelitian ini menggunakan pendekatan eksperimen dengan Desain penelitian yang digunakan Posttest-Only Contol Design. Populasi dalam penelitian ini adalah seluruh siswa kelas IV SDN Lamper Kidul 02 Semarang. Data yang dikumpulkan adalah nilai hasil belajar pembelajaran tematik di kelas kontrol maupun eksperimen dikumpulkan dengan menggunakan tes pilihan ganda satu jawaban benar (post-test). Data dianalisis dengan uji t, Hasil penelitian menunjukkan bahwa terdapat perbedaan secara signifikan terhadap hasil belajar pembelajaran tematik didapatkan ( $\mathrm{t}_{\text {hitung }}$ $\left.=5,51>\mathrm{t}_{\text {tabel }}=1,682\right)$ maka $\mathrm{H}_{0}$ ditolak dan $\mathrm{H}_{\mathrm{a}}$ diterima. Dengan demikian, dapat disimpulkan bahwa model pembelajaran TGT memberi pengaruh yang signifikan terhadap hasil belajar pembelajaran tematik pada siswa kelas IV SDN Lamper Kidul 02 Semarang.
\end{abstract}

Kata Kunci: hasil belajar, model pembelajaran Teams Games Tournament, pembelajaran tematik integratif.

\section{Abstract}

This study aims to determine the differences in learning outcomes between students learning thematic learning model that follows the TGT with students who take the direct instructional model fourth grade students of SDN Lamper Kidul 02 Semarang. This study used experimental approach to the study design used Contol Posttest -Only Design . The population in this study were all fourth grade students of SDN Lamper Kidul 02 Semarang. The data collected is the value of thematic and learning outcomes in the control and experimental classes were collected using a multiple-choice test answer correctly ( post-test) . Data were analyzed by $\mathrm{t}$ test, results showed that there were significant differences in the learning outcomes of thematic learning obtained $($ of $\mathrm{t}=5.51>\mathrm{t}$ table $=1.682)$ then $\mathrm{H} 0$ is rejected and $\mathrm{Ha}$ accepted . Thus, it can be concluded that the TGT learning model gave a significant effect on learning outcomes thematic learning in fourth grade students of SDN Lamper Kidul 02 Semarang.

Keywords: learning outcomes , learning model Teams Games Tournament , thematic integrative learning 


\section{PENDAHULUAN}

Pendidikan merupakan kebutuhan yang sangat penting bagi manusia. Dengan pendidikan, manusia dapat mencapai kemajuan di berbagai bidang yang pada akhirnya akan menempatkan seseorang pada kondisi yang lebih baik. Kemajuan suatu bangsa sangat ditentukan oleh kualitas sumber daya manusia, sedangkan kualitas sumber daya manusia tergantung dari kualitas pendidikannya. Menurut undang-undang no 20 tahun 2003 tentang sistem pendidikan nasional pasal 1 ayat 1 , sebagai berikut.

Pendidikan adalah usaha sadar dan terencana untuk mewujudkan suasana belajar dan proses pembelajaran agar peserta didik secara aktif mengembangkan potensi dirinya untuk memiliki kekuatan spiritual keagamaan, pengendalian diri, kepribadian, kecerdasan, akhlak mulia, serta keterampilan yang diperlukan dirinya, masyarakat, bangsa dan Negara.

Kemajuan Indonesia dapat tercapai melalui penataan pendidikan yang baik, dengan adanya peningkatan mutu pendidikan dapat menaikan harkat dan martabat manusia Indonesia. Untuk mencapainya, pembaharuan di Indonesia terus dilakukan dengan adanya perubahan kurikulum. Perubahan kurikulum 2013 merupakan langkah lanjutan pengembangan KBK (kurikulum berbasis kompetensi) yang telah dirintis pada tahun 2004 dan KTSP (Kurikulum tingkat satuan pendidikan) pada tahun 2006 yang mencakup kompetensi sikap, pengetahuan, dan keterampilan secara terpadu.

Pada kurikulum 2013 di SD atau MI menggunakan pendekatan pembelajaran tematik integratif dari kelas I sampai kelas VI. "Pembelajaran tematik integratif merupakan pendekatan pembelajaran yang mengintegrasikan berbagai kompetensi dari berbagai mata pelajaran ke dalam berbagai tema" (Kemendikbud, 2013:137). Dengan pembelajaran tematik integratif, guru berperan untuk menyatukan pemahaman serta wawasan siswa terhadap sejumlah materi pembelajaran tertentu. Selain itu guru juga memperhatikan aspek pengetahuan, sikap, dan ketrampilan yang diperoleh dari berbagai bidang studi tidak perlu dikemas dalam materi pembelajaran yang saling terpisah.

Harapan guru agar mutu pendidikan dapat ditingkatkan ternyata belum menampakkan hasil yang maksimal. Berdasarkan observasi yang dilakukan dengan guru kelas IV SDN Lamper Kidul 02 Semarang, diperoleh informasi bahwa hasil belajar siswa pada nilai ujian akhir semester ganjil sebagian besar sudah mencapai kriteria ketuntasan minimal tetapi juga ada beberapa siswa yang belum mampu mencapai kriteria ketuntasan minimal yang telah ditetapkan oleh sekolah. Hal tersebut disebabkan karena dalam kegiatan pembelajaran siswa kurang aktif dan guru hanya menggunakan model pembelajaran langsung (Direct Interaction).

Pada pembelajaran dengan model pembelajaran langsung, guru merupakan subyek utama kegiatan pembelajaran. Guru menjelaskan materi yang diajarkan dengan menggunakan contoh, kemudian siswa diminta untuk menyebutkan kembali dan menerapkan ke soal yang lain sesuai dengan contoh tersebut. Siswa selama kegiatan pembelajaran hanya mendengarkan semua hal yang didengarnya, mencatat materi yang telah diberikan dan mengerjakan segala 
sesuatu yang diperintahkam oleh guru. Sehingga selama pembelajaran siswa tidak ikut berpikir dan menggunakan pengalaman belajarnya.

Sebagai upaya meningkatkan hasil belajar siswa, perlu dikembangkan suatu pembelajaran yang tepat, sehingga dapat memberikan kesempatan bagi siswa untuk bertukar pendapat, bekerjasama dengan teman, berinteraksi dengan guru, menggunakan maupun mengingat kembali konsep yang telah dipelajari. Banyak cara yang dapat dilaksanakan agar siswa aktif dalam kegiatan pembelajaran, salah satunya yaitu dengan merubah paradigma pembelajaran. Guru bukan sebagai pusat pembelajaran tetapi sebagai pembimbing, motivator dan fasilitator. Selama kegiatan pembelajaran siswa yang dituntut untuk aktif, kreatif dan mandiri sehingga guru tidak menjadi peran utama dalam kegiatan pembelajaran di kelas. Oleh karena itu perlu dikembangkan sebuah model pembelajaran yang mampu meningkatkan keaktifan siswa dalam suatu kegiatan pembelajaran. Sehingga pada akhirnya bisa meningkatkan hasil belajar siswa.

Dengan adanya penggunaan model Teams Games Tournaments (TGT) dalam pembelajaran ini, peserta didik di harapkan dapat meningkatkan keaktifan, mampu mengikuti proses pembelajaran dengan baik, dan meningkatnya minat belajar siswa. Model TGT merupakan salah satu tipe atau model pembelajaran kooperatif yang mudah diterapkan, melibatkan aktivitas seluruh siswa tanpa harus ada perbedaan status, melibatkan peran siswa sebagai tutor sebaya dan mengandung unsur permainan, sehingga sesuai dengan karakteristik siswa SD.

Dalam model pembelajaran kooperatif tipe TGT secara positif mengandung unsur model kompetisi atau pertandingan yang dapat menimbulkan rasa cemas yang justru bisa memotivasi siswa untuk meningkatkan kegiatan belajar mereka. Sedikit rasa cemas memang mempunyai korelasi positif dengan motivasi belajar. (Anita lie, 2005: 24)

Sehingga peserta didik menjadi lebih kritis dalam memecahkan masalah serta lebih leluasa dalam melakukan eksplorasi, yang akhirnya dapat meningkatkan hasil belajar peserta didik karena ada motivasi untuk bersaing. Berdasarkan uraian di atas maka penulis tertarik untuk melakukan penelitian yang berjudul "Pengaruh Model Pembelajaran Teams Games Tournaments Terhadap Hasil Belajar Pembelajaran Tematik Integratif Siswa Kelas IV SDN Lamper Kidul 02 Semarang”.

\section{METODE PENELITIAN}

Penelitian ini dilaksanakan di SDN Lamper Kidul 02 Semarang. SDN Lamper Kidul 02 Semarang ini berada di jalan Sompok Baru Nomor 87, Kecamatan Semarang Selatan, Kota Semarang. Waktu penelitian ini dilaksanakan pada semester genap tahun pelajaran 2019/2020 tepatnya pada 11 februari - 21 februari 2020. Jenis Penelitian ini adalah penelitian eksperimen. Desain penelitian yang digunakan dalam penelitian ini adalah dengan true experimental design dengan model Postest-Only Control Design. Desain penelitian ini digambarkan sebagai berikut: 
Tabel 1

Desain/ rancangan penelitian

\begin{tabular}{|c|c|c|}
\hline Grup & Perlakuan & Post tes \\
\hline Kelas eksperimen & $\mathrm{X}_{\text {eksperimen }}$ & $\mathrm{O}_{2}$ \\
\hline Kelas kontrol & $\mathrm{X}_{\text {kontrol }}$ & $\mathrm{O}_{2}$ \\
\hline
\end{tabular}

Keterangan:

$\mathrm{X}_{\text {eksperimen: }}$ Perlakuan yang diberikan menggunakan model pembelajaran TGT.

$\mathrm{X}_{\mathrm{kontrol}}$ : Perlakuan yang diberikan dengan menggunakan model pembelajaran langsung

$\mathrm{O}_{2} \quad$ : Test setelah diberi perlakuan untuk kelompok eksperimen maupun kelompok kontrol (post-test).

Penelitian ini melibatkan dua variabel yaitu variabel bebas dan variabel terikat. Variabel bebas dalam penelitian ini yaitu model pembelajaran TGT, dan variabel terikat dalam penelitian ini adalah hasil belajar pembelajaran tematik integratif. Populasi adalah keseluruhan dari sasaran penelitian. (Soegeng, 2006: 70). Populasi dalam penelitian ini adalah seluruh peserta didik kelas IV SDN Lamper Kidul 02 Semarang tahun ajaran 2020/2021. Sampel adalah bagian atau anggota dari populasi yang diambil secara benar, karenanya dapat mewakili seluruh populasi secara sah/representatif (Soegeng, 2006: 71). Berdasarkan populasi di atas maka sampel dalam penelitian ini adalah anggota dari kelas IV SDN Lamper Kidul 02 Semarang, terdiri dari dua kelas yaitu kelas IVA dan IVB. Dengan ketentuan kelas IVA (sebagai kelas kontrol) terdiri dari 22 siswa, dan kelas IVB (sebagai kelas eksperimen) yang terdiri dari 23 siswa. Teknik sampling yang digunakan dalam penelitian ini adalah non probability sampling dengan jenis sampling jenuh. Sampling jenuh adalah teknik pengambilan sampel bila semua anggota populasi digunakan sebagai sampel. Biasanya dilakukan jika jumlah populasi relatif kecil atau penelitian yang ingin membuat generalisasi dengan kesalahan yang sangat kecil. Sampling jenuh juga sering disebut total sampling atau sensus.

Instrumen dalam suatu penelitian memiliki peranan yang sangat penting, karena data yang diperoleh sangat ditentukan oleh kualitas instrumen yang digunakan. Instrumen penelitian tersebut perlu untuk dilakukan uji instrumen. Secara singkat uji instrumen tes sebagai berikut :

1. Uji validitas

Validitas butir soal adalah butir tes dapat menjalankan fungsi pengukurannya dengan baik, hal ini dapat diketahui dari seberapa besar peran yang diberikan butir soal tes tersebut dalam mencapai keseluruhan skor seluruh tes. Untuk dapat mengetahui besar kecilnya peran tersebut adalah dengan jalan mengkorelasikan antara skor yang diperoleh dari butir tersebut dengan skor totalnya, menurut Arikunto (2009: 79) dengan menggunakan korelasi Point Biserial.

$$
\gamma_{p b i s}=\frac{M_{p}-M_{t}}{S_{t}} \sqrt{\frac{p}{q}}
$$


2. Reliabilitas

Reliabilitas merupakan keterandalan. Sebuah tes dikatakan memiliki keterandalan jika tes tersebut dipakai mengukur berulang-ulang hasilnya sama. Dengan demikian reliabilitas dapat diartikan dengan stabilitas atau tetap. Mencari reliabilitas instrument dengan menggunakan KR-20 (Arikunto, 2009: 101).

$$
r_{11}=\left(\frac{k}{k-1}\right)\left(\frac{S B^{2}-\sum P q}{S B^{2}}\right)
$$

3. Taraf kesukaran

Rumus yang digunakan sebagai berikut:

$$
I K=\frac{J B_{A}+J B_{B}}{J S_{A}+J S_{B}}
$$

Dengan $I K$ adalah indeks kesukaran, $J B_{A}$ adalah jumlah siswa yang menjawab benar pada butir soal pada kelompok atas, $J B_{B}$ adalah jumlah siswa yang menjawab benar pada butir soal pada kelompok bawah, $J S_{A}$ adalah banyak siswa pada kelompok atas, $J S_{B}$ adalah banyaknya siswa pada kelompok bawah.

4. Daya pembeda

Rumus yang digunakan sebagai berikut:

$$
D P=\frac{J B_{A}-J B_{B}}{J S_{A}}
$$

Dengan $D P$ adalah daya pembeda soal, $J B_{A}$ adalah jumlah siswa yang menjawab benar pada butir soal kelompok atas, $J B_{B}$ adalah jumlah siswa yang menjawab benar pada butir soal kelompok bawah, $J S_{A}$ adalah banyaknya siswa pada kelompok atas.

Analisis data adalah suatu langkah yang paling menentukan dalam penelitian karena analisis data berfungsi untuk menyimpulkan hasil penelitian.

1. Analisis Data Awal

Sebelum peneliti menentukan teknik analisis statistik yang digunakan, terlebih dahulu peneliti memeriksa keabsahan sampel. Cara yang digunakan untuk memeriksa keabsahan sampel tersebut adalah uji normalitas, uji homogenitas, dan uji kesamaan dua rata-rata.

b. Uji Normalitas

Uji normalitas ini digunakan untuk mengetahui data awal (rata-rata nilai prestasi peserta didik) berdistribusi secara normal atau tidak, dilakukan uji normalitas dengan uji Chi-Kuadrat, adapun langkah-langkah uji Chi-Kuadrat menurut sugiyono (2010: 241) adalah sebagai berikut:

1) Menentukan jumlah kelas interval. Dalam hal ini jumlah kelas intervalnya $=6$, karena luas kurve normal dibagi menjadi enam yang masing-masing luasnya adalah $2,7 \% ; 13,34 \% ; 33,96 \% ; 33,96 \% ; 13,34 \% ; 2,7 \%$. 
2) Menentukan panjang kelas interval yaitu data terbesar- data terkecil dibagi dengan jumlah kelas interval enam.

3) Menyusun ke dalam tabel distribusi frekuensi.

4) Menghitung frekuensi yang diharapkan $\left(f_{h}\right)$, dengan cara mengalikan presentase luas tiap bidang kurve normal dengan jumlah anggota sampel.

5) Memasukkan harga-harga $f_{h}$ ke dalam tabel kolom $f_{h}$ sekaligus menghitung harga-harga $\left(f_{0}-f_{h}\right)$ dan $\frac{\left(f_{0}-f_{h}\right)^{2}}{f_{h}}$ menjumlahkannya. Harga $\frac{\left(f_{0}-f_{h}\right)^{2}}{f_{h}}$ adalah merupakan harga Chi Kuadrat $\left(\chi_{\mathrm{h}}^{2}\right)$ hitung.

6) Membandingkan harga Chi Kuadrat hitung dengan Chi Kuadrat tabel. Bila harga Chi Kuadrat hitung lebih kecil atau sama dengan harga Chi kuadrat tabel $\left(\chi_{\mathrm{h}}{ }^{2} \leq \chi_{\mathrm{t}}^{2}\right)$, maka distribusi data dinyatakan normal dan bila lebih besar (>) dinyatakan tidak normal.

c. Uji Homogenitas

Uji homogenitas dilakukan untuk mengetahui apakah data tersebut homogen atau tidak. Pengujian homogen data dilakukan dengan Uji Bartlett. Adapun langkah-langkahnya menurut Sudjana (2005: 262) sebagai berikut:

1) Data dikelompokkan untuk menentukan frekuensi varians dan jumlah kelas.

2) Membuat tabel uji barlett. Harga-harga yang berlaku untuk uji barlett Hipotesis yang diajukan adalah:

Ho : $\sigma_{1}^{2}=\sigma_{2}^{2}=\sigma_{3}^{2}$

Ho : paling sedikit satu tanda sama dengan tidak berlaku

3) Menghitung $S^{2}$ dari masing-masing kelas.

4) Menghitung varian gabungan dari semua kelas dengan rumus:

$S_{g}^{2}=\left(\frac{\sum\left(n_{i}-1\right) S_{i}^{2}}{\sum\left(n_{1}-1\right)}\right)$

5) Menghitung harga satuan $B$ dengan rumus:

$$
B=\left(\log S_{g}^{2}\right)\left(\sum\left(n_{i}-1\right)\right)
$$

6) Menghitung nilai statistik chi kuadrat $\left(x^{2}\right)$ dengan rumus:

$$
\chi^{2}=(\ln 10)\left(B-\sum\left(n_{i}-1\right) \log S_{i}^{2}\right)
$$

Dengan kriteria jika $\chi^{2}$ hitung $<\chi^{2}$ tabel dengan taraf signifikansi 5\% maka dapat dikatakan homogen (Sudjana, 2005: 261).

Dalam pengujian homogenitas sampel, apabila varian yang dimiliki oleh sampelsampel yang bersangkutan tidak jauh berbeda, maka sampel-sampel tersebut cukup homogen. Uji homogenitas dilakukan pada data rata-rata nilai prestasi peserta didik 
sebelum perlakuan pada semester ganjil kelas IV SDN Lamper Kidul 02 Semarang tahun ajaran 2019/2020.

2. Analisis Tahap Akhir

Analisis data akhir menggunakan uji hipotesis, karena yang dibandingkan adalah dua hal yang benar-benar berbeda, yaitu antara pembelajaran dikelas eksperimen dengan perlakuan model pembelajaran Teams Games Tournament, sedangkan dikelas kontrol dengan pembelajaran direct intraction.

Tahapan dalam analisis akhir meliputi:

a. Uji Normalitas

Langkah-langkah normalitas kedua sama dengan langkah uji normalitas data awal

b. Uji Homogenitas

Langkah-langkah homogenitas kedua sama dengan langkah uji homogenitas data awal.

c. Uji Hipotesis

Teknik untuk menguji hipotesis dengan melakukan uji $-\mathrm{t}$. Dimana uji $-\mathrm{t}$ digunakan untuk menguji perbedaan rata-rata kelompok eksperimen

dengan kelompok kontrol. Uji ini dilakukan dengan mempersyaratkan data yang akan diuji berdistribusi secara normal.

Uji kesamaan dua rata-rata dilakukan pada data post-tes kelompok eksperimen dan kelompok kontrol yaitu untuk menguji ada perbedaan rata-rata post-test hasil belajar pembelajaran tematik integratif pada tema indahnya negeriku dan dengan sub tema keanekaragaman hewan dan tumbuhan dari kedua kelompok setelah diberi perlakuan.

Uji hipotesis ini menggunakan uji satu pihak (pihak kanan), yang diuji adalah: $\mathrm{H}_{0}: \mu_{\mathrm{o}}=\mu_{\mathrm{k}}=$ nilai rata-rata kelompok eksperimen sama dengan nilai rata-rata post-test kelompok kontrol.

$\mathrm{H}_{1}: \mu_{\mathrm{o}}>\mu_{\mathrm{k}}=$ nilai rata-rata kelompok eksperimen lebih dari nilai rata-rata post-test kelompok kontrol.

Setelah kedua sampel sama atau berbeda, maka untuk selanjutnya data dianalisis dengan uji hipotesis penelitian, maka rumus $t$-test yang digunakan: (Sudjana, 2005: 239)

$$
t=\frac{\bar{X}_{e}-\bar{X}_{k}}{S \sqrt{\frac{1}{n_{e}}+\frac{1}{n_{k}}}}
$$

Dengan:

$$
S^{2}=\frac{\left(n_{e}-1\right) S_{e}^{2}+\left(n_{k}-1\right) S_{k}^{2}}{n_{e}+n_{k}-2}
$$




$$
\begin{aligned}
S^{2} & =\frac{n_{e} \sum X_{e}-\left(\sum e\right)^{2}}{n_{e_{\left(n_{e}-1\right)}}} \\
S_{k}^{2} & =\frac{n_{k} \sum X_{k}-\left(\sum X_{k}\right)^{2}}{n_{k_{(n k-1)}}} \\
S_{e}^{2} & =\frac{n_{e} \sum X_{e}-\left(\sum X_{e}\right)^{2}}{n_{e_{(n e-1)}}}
\end{aligned}
$$

Dengan $\bar{X}_{e}$ adalah rata-rata kelompok eksperimen, $\bar{X}_{k}$ adalah rata-rata kelompok kontrol, $\mathrm{n}_{\mathrm{e}}$ adalah jumlah anggota kelompok eksperimen, $\mathrm{n}_{\mathrm{k}}$ adalah jumlah anggota kelompok kontrol, $S^{2}{ }_{e}$ adalah varian kelompok eksperimen, $S^{2}{ }_{k}$ adalah varian kelompok kontrol.

Derajat kebebasan untuk tabel distribusi t adalah $\left(\mathrm{n}_{1}+\mathrm{n}_{2}-2\right)$ dengan peluang (1$\alpha), \alpha$ taraf signifikan (Sudjana, 2005: 234). Dalam penelitian ini diambil taraf signifikan $\alpha=5 \%$, dengan kriteria pengujian sebagai berikut:

a. Terima Ho jika $t_{\text {hitung }}<\mathrm{t}_{(1-} \boldsymbol{\alpha}_{\text {(ne+nk-2)tabel, }}$ hal ini berarti tidak ada perbedaan nilai ratarata post-test antara kelompok eksperimen dan kelompok kontrol.

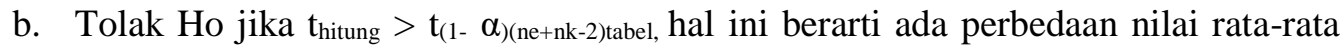
post-test antara kelompok eksperimen dan kelompok kontrol.

\section{HASIL DAN PEMBAHASAN}

1. Data Nilai Awal Kelas Kontrol

Data nilai awal diambil dari rata-rata nilai prestasi peserta didik pada semester ganjil tahun pelajaran 2020/2021. Dari data tersebut diperoleh nilai tertinggi 77 dan nilai terendah 62. Rentang nilai (R) adalah 15, banyaknya kelas interval (k) diambil 6 kelas, panjang kelas interval (p) diambil 2, jumlah peserta didik (N) adalah 22, sehingga nilai rata-rata prestasi peserta didik $\bar{X}=70,09$.

2. Data Nilai Awal Kelas Eksperimen

Data nilai awal diambil dari rata-rata nilai prestasi peserta didik pada semester ganjil tahun pelajaran 2020/2021. Dari data tersebut diperoleh nilai tertinggi 79 dan nilai terendah 74. Rentang nilai (R) adalah 15, banyaknya kelas interval (k) diambil 6 kelas, panjang kelas interval (p) diambil 3, jumlah peserta didik $(\mathrm{N})$ adalah 23, sehingga nilai rata-rata prestasi peserta didik $\bar{X}=72,30$.

3. Data Nilai Akhir Kelas Kontrol

Pengambilan nilai akhir dalam penelitian ini didapat dari nilai post-test yang diambil dari hasil pengerjaan soal oleh peserta didik setelah peserta didik mendapat perlakuan (kelas kontrol dengan model pembelajaran langsung). Jumlah soal post-test yaitu 30 soal berupa pilihan ganda. Nilai tertinggi 87 dan nilai terendah 60. Rentang nilai (R) adalah 27, banyaknya kelas interval (k) diambil 6 kelas, panjang kelas interval (p) diambil 5, jumlah 
peserta didik $(\mathrm{N})$ adalah 22. Sehingga nilai rata-rata tes akhir kelas kontrol peserta didik $\bar{X}$ $=73,81$.

4. Data Nilai Akhir Kelas Eksperimen

Pengambilan nilai akhir dalam penelitian ini didapat dari nilai post-test yang diambil dari hasil pengerjaan soal oleh peserta didik setelah peserta didik mendapat perlakuan (kelas eksperimen dengan model pembelajaran TGT). Jumlah soal post-test yaitu 30 soal berupa pilihan ganda. Nilai tertinggi 93 dan nilai terendah 70. Rentang nilai (R) adalah 23, banyaknya kelas interval (k) diambil 6 kelas, panjang kelas interval (p) diambil 4, jumlah peserta didik $(\mathrm{N})$ adalah 23. Sehingga nilai rata-rata tes akhir kelas kontrol peserta didik $\bar{X}$ $=83,30$.

Uji Persyaratan Analisis Data

1. Analisis Awal

a. Uji Normalitas

$\mathrm{H}_{0}=$ Data berdistribusi normal

$\mathrm{H}_{\mathrm{a}}=$ Data tidak berdistribusi normal

Pengujian normalitas menggunakan Chi Kuadrat. Untuk menentukan kriteria pengujian digunakan distribusi Chi Kuadrat dengan $\mathrm{dk}=(\mathrm{n}-1)$ dan taraf $\alpha=5 \%$. Hasil perhitungan data awal sebagai berikut:

Tabel 4.5

Hasil Perhitungan Chi Kuadrat Nilai Awal

\begin{tabular}{ccccc}
\hline No & Kelas & $\chi^{2}$ hitung & $\chi^{2}$ tabel & Keterangan \\
\hline 1 & IV A & 3,659 & 11,070 & Normal \\
2 & IV B & 3,755 & 11,070 & Normal \\
\hline
\end{tabular}

b. Uji Homogenitas

Uji Homogenitas yang digunakan adalah Uji Barlett. Data yang digunakan adalah kelompok yang berdistribusi normal, dengan hipotesis sebagai berikut:

$\mathrm{H}_{0}: \square_{\mathrm{k}}=\square_{\square \square}($ Varians Homogen $)$

$\mathrm{H}_{1:} \square_{\mathrm{k}} \square \square_{\square \square}($ Varians tidak Homogen)

Dengan kriteria pengujian adalah $\chi^{2}$ hitung $<\chi^{2}$ tabel maka $\mathrm{H}_{0}$ diterima.untuk taraf nyata $\alpha=5 \%$ dengan $\mathrm{dk}=\mathrm{k}-1$. Diperoleh hasil perhitungan $\chi^{2}$ hitung 0,081 dan $\chi^{2}$ tabel 3,841 . Maka $\mathrm{H}_{0}$ diterima dan dapat disimpulakan bahwa kedua kelompok berasal dari populasi yang varians sama (Homogen).

2. Analisis Akhir

a. Uji Normalitas

Pada penelitian eksperimen ini, kondisi akhir dari kedua sampel yang diberi perlakuan berbeda akan dinilai menggunakan post-test. Dari nilai post- 
test diperoleh rata-rata untuk kelas ekperimen dan kelas kontrol. Pengujian normalitas menggunakan Chi Kuadrat. Untuk menentukan kriteria pengujian digunakan distribusi Chi Kuadrat dengan $\mathrm{dk}=(\mathrm{n}-1)$ dan taraf $\alpha=5 \%$. Hasil perhitungan akhir sebagai berikut:

Tabel 4. 6

Hasil Perhitungan Chi Kuadrat Nilai Akhir

\begin{tabular}{ccccc}
\hline No & Kelas & $\chi^{2}$ hitung & $\chi^{2}$ tabel & Keterangan \\
\hline 1 & IV A & 8,637 & 11,070 & Normal \\
2 & IV B & 8,330 & 11,070 & Normal \\
\hline
\end{tabular}

b. Uji Homogenitas

Uji Homogenitas yang digunakan adalah Uji Barlett. Data yang digunakan adalah kelompok yang berdistribusi normal, dengan hipotesis sebagai berikut:

$\mathrm{H}_{0}: \square_{\mathrm{k}}=\square_{\square \square}($ Varians Homogen $)$

$\mathrm{H}_{1:} \square_{\mathrm{k}} \square \square \square_{\square \square}($ Varians tidak Homogen)

Dengan kriteria pengujian adalah $\chi^{2}$ hitung $<\chi^{2}$ tabel maka $\mathrm{H}_{0}$ diterima.untuk taraf nyata $\alpha=5 \%$ dengan $\mathrm{dk}=\mathrm{k}-1$. Diperoleh hasil perhitungan $\chi^{2}$ hitung 2,355 dan $\chi^{2}$ tabel 3,841. Maka $\mathrm{H}_{0}$ diterima dan dapat disimpulakan bahwa kedua kelompok berasal dari populasi yang varians sama (Homogen).

Deskripsi data hasil belajar kelas eksperimen dan kelas kontrol disajikan pada tabel 2.

Tabel 2

Data hasil belajar kelas eksperimen dan kelas kontrol

\begin{tabular}{ccc}
\hline Keterangan & Eksperimen & Kontrol \\
\hline Jumlah & 1916 & 1624 \\
$\mathrm{~N}$ & 23 & 22 \\
$\square \mathrm{X}$ & 83.3043478 & 73.8181818 \\
Varian $\left(\mathrm{S}^{2}\right)$ & 25.94862 & 50.5368 \\
Standar deviasi (S) & 5.0939788 & 7.10892397 \\
\hline
\end{tabular}

Berdasarkan hasil perhitungan uji-t diperoleh $t_{\text {hitung }}=5,51$ sedangkan $t_{\text {tabel }}=1,682$ dengan taraf nyata $\alpha=5 \%$ dan $\mathrm{dk}=43$. Hal ini menunjukkan bahwa $\mathrm{t}_{\text {hitung }}>\mathrm{t}_{\text {tabel. }}$. Jadi Ho: $\mu_{\mathrm{o}}=$ $\mu_{\mathrm{k}}$ ditolak dan $\mathrm{H}_{1}: \mu_{\mathrm{o}}>\mu_{\mathrm{k}}$ diterima. Hal ini berarti bahwa rata-rata hasil belajar peserta didik kelas eksperimen yang diajar dengan model TGT tema cita-citaku, sub tema aku dan cita-citaku, pada pembelajaran 1-6 siswa kelas IV SDN Lamper Kidul 02 Semarang berbeda secara nyata dari rata-rata hasil belajar peserta didik kelas kontrol.

Berdasarkan perhitungan analisis statistik di atas, maka di dalam penelitian ini akan dijelaskan mengenai hasil analisis data, yaitu: data tes yang digunakan untuk nilai awal dalam penelitian ini baik kelas eksperimen maupun kelas kontrol berasal dari nilai rata-rata prestasi peserta didik pada semester ganjil di SDN Lamper Kidul 02 tahun ajaran 2019/2020 dengan 
nilai rata-rata untuk kelas kontrol (IV A) adalah 70,09 dan standar deviasi 3,85 sedangkan ratarata untuk kelas eksperimen (IV B) adalah 72,30 dan standar deviasi 3,62. Nilai awal tersebut kemudian dilakukan uji persyaratan yakni diuji normalitas dan uji homogenitas untuk mengetahui apakah nilai tersebut berdistribusi normal, memiliki varians yang sama dan memiliki kemampuan awal yang sama sehingga nilai awal tersebut telah memenuhi persyaratan sehingga dapat dilanjutkan untuk diberi perlakuan.

Pemberian perlakuan dilakukan pada kelas ekperimen. Pada kelas eksperimen diberi pembelajaran dengan menggunakan model pembelajaran TGT sementara pada kelas kontrol tidak diberi perlakuan dan kegiatan pembelajaran menggunakan model pembelajaran langsung atau Direct Instruction. Hasil belajar yang diperoleh siswa setelah adanya perlakuan (nilai akhir) menunjukkan bahwa kelas ekperimen memiliki nilai rata-rata 73,81 untuk kelas kontrol (IV A) adalah dan standar deviasi 7,10 sedangkan rata-rata untuk kelas eksperimen (IV B) adalah 83,30 dan standar deviasi 5,09. Berdasarkan hasil analisis akhir uji-t menurut sudjana (2005: 243) dengan taraf signifikan 5\% didapatkan $\mathrm{t}_{\text {hitung }}=5,51$ dan $\mathrm{t}_{\text {tabel }}=1,682$. Jadi, $\mathrm{t}_{\text {hitung }}>\mathrm{t}_{\text {tabel. }}$. Sehingga diperoleh kesimpulan bahwa hipotesis $\mathrm{H}_{\mathrm{O}}$ ditolak dan $\mathrm{H}_{\mathrm{a}}$ diterima. Dapat disimpulkan bahwa penelitian ini dapat menguji kebenaran hipotesis yaitu terdapat pengaruh model pembelajaran TGT terhadap hasil belajar pembelajaran tematik pada tema cita-citaku, sub tema aku dan citacitaku, pada pembelajaran 1-6 siswa kelas IV SDN Lamper Kidul 02 Semarang tahun pelajaran 2019/2020.

\section{KESIMPULAN}

Ada pengaruh model pembelajaran Teams Games Tournament terhadap hasil belajar pembelajaran tematik dengan tema cita-citaku, sub tema aku dan cita-citaku, pada pembelajaran 1-6 siswa kelas IV SDN Lamper Kidul 02 Semarang tahun pelajaran 2019/2020.

Ada perbedaan hasil belajar siswa yang menggunakan model pembelajaran Teams Games Tournament dengan hasil belajar siswa yang menggunakan model pembelajaran langsung atau Direct Instruction pada pembelajaran 1-6 siswa kelas IV SDN Lamper Kidul 02 Semarang tahun pelajaran 2019/2020.

Penelitian eksperimen ini, diharapkan guru dapat mencoba menggunakan model Teams Games Tournament agar bisa diterapkan ke dalam materi pelajaran lain. Tujuannya agar peserta didik dapat meningkatkan hasil belajar peserta didik dapat menjadi lebih baik.

Pembelajaran yang menggunakan model Teams Games Tournament melibatkan semua peserta didik, maka dalam pelaksanaannya guru harus mempersiapkan dengan sebaik mungkin.

\section{DAFTAR PUSTAKA}

Arikunto, Suharsimi. 2009. Dasar-Dasar Evaluasi Pendidikan. Jakara: Bumi Aksara

Catarina Tri Anni, dkk. 2004. Psikologi Belajar, Semarang: UPT MKK UNNES, 2004). 
Cahyaningrum, Mega. 2013. Pengaruh Model Pembelajaran Kooperatif Tipe TGT (Teams Games Tournament) terhadap Hasil Belajar Matematika Siswa Kelas IV SD Negeri Gabus 01 Kabupaten Pati.Skripsi. Semarang: IKIP PGRI Semarang

Depdiknas. 2007. Peraturan Menteri Pendidikan Nasional. Jakarta: Depdiknas.

Dimyati dan Mudjiono. 2009. Belajar dan Pembelajaran. Jakarta: Rineka Cipta

Hamalik, Oemar. 2008. Kurikulum dan Pembelajaran. Jakarta: Bumi Aksara

Hamdani. 2010. Strategi Belajar Mengajar. Bandung: CV Pustaka Setia

Kemendikbud. 2013. Dokumentasi kurikulum 2013.

Diana Puspa Karitas, dkk. Cita- citaku Buku Siswa. Tematik Terpadu. Jakarta: Kementerian Pendidikan dan Kebudayaan

Diana Puspa Karitas, dkk. Cita- citaku Buku Guru Tematik Terpadu. Jakarta:

Kementerian Pendidikan dan Kebudayaan

Lie, Anita. 2005. Cooperative Learning, Mempraktikkan Cooperative Learning di Ruang-ruang Kelas, Jakarta: PT. Gramedia Widiasarana.

Mahmuddin, Desember 23, 2009, http://www.google.com//Strategi Pembelajaran Kooperatif Tipe Teams Games-Tournament TGT.html. Didownload 10 September 2011 jam 13.30

Slameto. 2010. Belajar dan Faktor-faktor yang Mempengaruhinya. Jakarta: Rineka Cipta.

Slavin, Robert. 2005. Cooperative Learning Teori, Riset dan Praktik. Bandung: Nusa Media

Soegeng. A.Y. 2006. Dasar-dasar Penelitian. Semarang: IKIP PGRI PRESS

Sudjana, nana. 2005. Metode Statistika. Bandung: Tarsinto.

-. 2013. Penilaian Hasil Proses Belajar Mengajar. Bandung: Remaja Rosdakarya.

Sugiyono. 2010. Metodologi Penelitian Pendidikan. Bandung: Alfabeta

Suprijono, agus. 2009. Cooperative Learning teori dan aplikasi paikem. Yogyakarta : Pustaka belajar

Sutirjo dkk. 2005. Tematik: Pembelajaran Efektif dalam Kurikulum 2004. Malang: Bayumedia Publishing.

Trianto. 2011. Model Pembelajaran Terpadu. Jakarta: Bumi Aksara

Winkel, W.S. 1996. Psikologi Pengajaran. Jakarta: Grasindo. 